\title{
A TECNOLOGIA COMO PROBLEMA NA EDUCAÇÃO em CiênCIA, TeCNologia e SOCIEDAde: ANÁLISES DE UMA OFICINA DE LEITURA NA FORMAÇÃO DE PROFESSORES DE CIÊNCIAS
}

\author{
Bethania Medeiros Geremias \\ Universidade Federal de Viçosa (UFV), Viçosa, Minas Gerais, Brasil \\ SuZANI CASSIANI \\ Universidade Federal de Santa Catarina (UFSC), \\ Florianópolis, Santa Catarina, Brasil
}

Resumo: A partir de uma Perspectiva Discursiva em Educação em Ciência, Tecnologia e Sociedade (CTS), investigamos os sentidos sobre tecnologia produzidos durante a análise conjunta de uma animação educativa sobre a origem e produção do artefato papel, realizada com integrantes do grupo Observatório da Educação, da Universidade Federal de Santa Catarina - Ciências (OBEDUFSC - Ciências). Na análise desse processo, percebemos a materialização, no discurso dos sujeitos da pesquisa, de questões debatidas nos estudos CTS, tais como: i) problema x solução tecnológica; ii) leitura salvacionista $x$ destrutiva da tecnologia; iii) silenciamentos das relações CTS. Em síntese, a pesquisa proporcionou elementos para problematizar e compreender o que é dito, mas, também, os silêncios sobre tecnologia e suas questões, contribuindo para pensar o desenvolvimento de temas tecnológicos na formação de professores de Ciências.

PALAVRAS-CHAVE: Educação CTS. Formação de professores de Ciências. Tecnologia. Papel. 
INTRODUÇÃO

A problematização da tecnologia como campo de conhecimento, bem como o estudo e a elaboração de propostas de inserção de suas questões na Educação Científica e Tecnológica (ECT) têm gerado maiores debates nas pesquisas acadêmicas, principalmente naquelas que enfatizam a necessidade de que sejam consideradas as relações Ciência, Tecnologia e Sociedade (CTS).

Historicamente, a necessidade de compreender essas relações originou o Movimento CTS, após a Segunda Guerra Mundial, a partir de algumas iniciativas e percepções sociais que questionavam mais enfaticamente os modos como a ciência e a tecnologia vinham se produzindo e seus efeitos, gerando mal-estar mesmo entre os próprios cientistas (FENSHAM, 1988).

Associados a esses debates internalistas, começaram a proliferar movimentos sociais no fim da década de 1960, tais como os liderados por Lewis Mumford e Jacques Ellul, para os quais a ciência e a tecnologia produzem efeitos nocivos à sociedade; Raquel Carson, uma das principais representantes do movimento ambientalista; Ralph Nader, com trabalhos direcionados ao movimento dos consumidores; Theodore Roszak e Alvin Toffler, chamando a atenção para a não neutralidade da ciência e da tecnologia e para seus impactos sociais (VELHO; VELHO, 2002).

Segundo Auler e Delizoicov (2006), essas ideias estão na base da construção de um campo conhecido como Educação CTS, na qual se concebe que o papel primordial da ECT é o de criar espaços educativos que possibilitem uma leitura crítica do mundo contemporâneo. Nessa perspectiva, a ECT precisa superar seu viés conteudista por meio de dinâmicas educativas que problematizem e transformem compreensões históricas dominantes de ciência e de tecnologia, associadas à tecnocracia, ao determinismo tecnológico e às imagens salvacionistas imputadas a essas áreas.

Tais finalidades acompanham a dinâmica da Educação CTS desenvolvida em contexto latino-americano, apesar de hoje identificarmos uma polissemia do termo e uma produção de distintas abordagens, configuradas por uma pluralidade de filiações teóricas e metodológicas (CASSIANI et al., 2014; ABREU; FERNANDES; MARTINS, 2013; STRIEDER, 2012).

Alguns pesquisadores criticam a pouca atenção dada ao campo tecnológico na Educação CTS (CASSIANI et al., 2014; FERNÁNDEZ et al., 2003; FENSHAM, 1988; LAYTON, 1988), apesar da presença do T no centro do acrônimo. As possíveis explicações se relacionam com dois fatores principais: i) com o fato de a Educação CTS ter sido introduzida mais amplamente na área de 
Ensino de Ciências, na qual o foco era atribuído à relação ciência-sociedade, silenciando a tecnologia nesse processo (CASSIANI et al., 2014; NIEZWIDA, 2012); ii) com interpretações de tecnologia como ciência aplicada, artefatos da informática ou qualquer outro artefato (NASCIMENTO; LINSINGEN, 2006; FERNÁNDEZ et al., 2003; ACEVEDO-DÍAZ et al., 2003; LAYTON, 1988).

Conforme Layton (1998), é preciso revalorizar a tecnologia nas abordagens CTS, reconhecendo-a como um campo específico de conhecimento, não subordinado à ciência. Na sua acepção, a tecnologia é um componente fundamental para a formação geral dos estudantes por ser um tema transversal, presente em todas as práticas sociais.

Em nossos estudos de revisão confirmamos esses resultados e discussões, mas observamos que na área de ECT o sentido de tecnologia dominante é aquele que faz referência às Tecnologias da Informação e da Comunicação (TIC). Acevedo-Díaz et al. (2003, p. 355, grifo nosso) chamam a atenção para essa leitura e abordagem da tecnologia no Ensino de Ciências, pois consideram que "introduzir a educação tecnológica não é o mesmo que usar tecnologia na educação científica e vai muito mais além desta opção".

As pesquisas aqui debatidas demonstram a relevância de se ampliar a discussão sobre tecnologia na Educação CTS. Neste artigo, socializamos um recorte dos resultados da análise de uma animação educativa intitulada “De onde vem o papel?", realizada com integrantes de um projeto de formação inicial e continuada, financiado pelo programa Observatório da Educação (OBEDUC), da Coordenação de Aperfeiçoamento de Pessoal de Nível Superior (Capes). A atividade, norteada pela Perspectiva Discursiva em Educação CTS (LINSINGEN; CASSIANI, 2010), integrou algumas das dinâmicas de leituras de textos, elaboradas pela primeira pesquisadora, com o objetivo geral de mobilizar sentidos sobre tecnologia na formação de professores de Ciências.

A perspectiva teórico-metodológica adotada durante todo o processo de pesquisa, bem como a descrição e discussão de parte desse trabalho, permitirá melhor compreender o objeto da pesquisa e os nossos desafios.

\section{EDUCAÇÃO CTS: UMA PERSPECTIVA DISCURSIVA}

A Perspectiva Discursiva em Educação CTS realiza interlocuções entre os Estudos Sociais da Ciência e da Tecnologia (ESCT) latino-americanos e a Análise de Discurso (AD), desenvolvida por Michel Pêcheux (França) e atualizada por Eni Orlandi (Brasil). Por meio desse diálogo temos buscado 
"promover um trabalho pedagógico no ensino de ciências que caminhe para se pensar, propor e questionar possíveis implicações sociais das ciências e das tecnologias" (CASSIANI et al., 2014, p. 2).

Os ESCT latino-americanos envolvem distintas abordagens teórico-metodológicas e atuam nos campos fronteiriços do conhecimento científico e tecnológico para compreendê-los como realmente são. Destacam-se os trabalhos de Bruno Latour, David Bloor, Michel Callon, Barry Barnes, Steven Shapin, Trevor Pinch, Pierre Bourdieu, Karin Knorr-Cetina e Harry Collins (PREMEBIDA; NEVES; ALMEIDA, 2011, p. 25).

Conforme Thomas (2010), esses estudos estão se fortalecendo na América Latina, principalmente os etnográficos e sociológicos. Porém, observamos, igualmente, um crescimento de trabalhos amparados na Filosofia da Tecnologia, por meio da Teoria Crítica da Tecnologia (TCT), desenvolvida por Andrew Feenberg. ATCT se propõe a problematizar e questionar a tecnologia para deslocar, por meio da ação e do pensamento crítico, as interpretações instrumentalistas, neutras e deterministas de tecnologia. De acordo com Neder (2013), ela contribui com os ESCT ao propor bases teóricas e cognitivas para compreender as complexas interações entre tecnologia e sociedade e superar o determinismo tecnológico.

Nos ESCT a relação entre tecnologia e sociedade é compreendida como sociotécnica. Conforme Thomas (2010), "nossas sociedades são tecnológicas assim como nossas tecnologias são sociais. Somos seres sociotécnicos" (THOMAS, 2010, p. 12). Para Benakouche (1999), esse efeito de separação entre T e $S$ tem relação com a metáfora de impacto social da técnica e se produziu como oposição ao sentido determinista de impacto tecnológico que atribuiu uma autonomia social que a técnica não possui. Desse modo, a responsabilização da técnica pelas mazelas ou benfeitorias sociais é, para a autora, efeito de um desconhecimento sobre a forma como ela é construída, ou seja, por atores sociais, no contexto da própria sociedade.

A compreensão da separação entre tecnologia e sociedade como um efeito tem relação com a noção de discurso na $A D$, ou seja, como "efeito de sentidos entre locutores" (ORLANDI, 2012). É no discurso, materializado na língua, que podemos constatar o modo social de produção da linguagem enquanto materialidade dos imaginários (ideologias) subjacentes ao contexto sociocultural de cada época.

Para podermos aceder ao discurso e compreender o modo como os sentidos se produzem, necessitamos analisar as condições de produção dos enunciados. Estas são compreendidas como amplas (sócio-históricas) e 
estritas (quem diz, o quê, para quê, quando, onde) dos enunciados. São elas que possibilitam um trabalho com a memória discursiva - o interdiscurso -, mecanismo que faz funcionar as relações que os sujeitos estabelecem com os sentidos (ORLANDI, 2009).

Nesse processo de buscar compreender as relações de sentido, estabelecidas pelos sujeitos ao lerem a animação "De onde vem o papel?", promovemos não somente uma leitura do que foi dito no material na forma de texto verbal ou imagético, mas também dos silêncios. Conforme Orlandi (2007), o silêncio na AD não remete ao dito, pois permanece sempre silêncio, significando.

O caráter polissêmico da tecnologia se materializa, assim, no momento em que os sujeitos fazem remissões a ela, de acordo com suas filiações teóricas e leituras anteriores. Essa polissemia se manifesta na forma de diferentes imaginários sobre tecnologia, produzidos historicamente em diversas áreas do conhecimento humano.

No trabalho desenvolvido, a AD nos proporcionou elementos teóricos para compreender as continuidades e descontinuidades na produção de sentidos sobre tecnologia e o importante papel da linguagem no processo de produção e circulação do conhecimento tecnológico. O modo como as pessoas pensam, se relacionam e vivem, ou seja, atribuem sentido às coisas que estão postas no mundo - e a tecnologia como constituinte da existência humana -, é constantemente fornecido pela linguagem, pois é na língua que os discursos se materializam e é nos discursos que a ideologia (imaginário) de cada época se produz/reproduz (ORLANDI, 2009).

Tendo em vista essas interlocuções entre ESCT e AD, apresentamos um recorte do modo como investigamos a produção de sentidos sobre tecnologia na formação de professores de Ciências, bem como das análises das discussões realizadas com e pelos integrantes do OBEDUFSC - Ciências em torno da animação educativa "De onde vem o papel?".

As animações são aqui concebidas como um conjunto de linguagens acontecendo e constituindo sentido entre locutores (ORLANDI, 2006). Conforme a autora, as materialidades digitais produzem sentidos diferentes daqueles do texto escrito, ao instaurarem a memória metálica, ou seja, aquela "produzida pela mídia [...] por um construto técnico" (ORLANDI, 2006, p. 5). Ao considerar essas especificidades, Fischer (2007, p. 296) chama a atenção para a necessidade de inserir os professores em atividades que envolvam uma leitura crítica desses materiais, para que os reconheçam como produtores de "efeitos em nós". 
No âmbito do Ensino de Ciências, Ramos (2006, p. 6) sugere que a escola seja um "espaço de possível debate dos discursos midiáticos, com a intenção de problematizar as questões científicas e tecnológicas". Neste trabaIho evidenciamos que os debates sobre tecnologia, engendrados no campo dos Estudos e da Educação CTS, trouxeram elementos para problematizar questões tecnológicas no processo da leitura da animação citada, na formação de professores de Ciências, bem como para compreender o funcionamento dos discursos e os seus efeitos de sentido nos dizeres desses sujeitos.

\section{TRAJETOS, OBJETOS E SUJEITOS}

A Perspectiva Discursiva em Educação CTS, abordada anteriormente, é compreendida como referencial teórico-metodológico, inserindo-se, por sua relação com os estudos do discurso, no tipo de pesquisa qualitativa (ORLANDI, 2008). Ela norteou não somente a pesquisa, mas também os estudos e as atividades desenvolvidos com os integrantes do grupo Observatório Educação da Universidade Federal de Santa Catarina - Ciências (OBEDUFSC - Ciências).

Esse grupo integra o projeto Reflexões e práticas pedagógicas nas ciências naturais: leituras das avaliações nacionais como subsídios da educação (2013-2017), financiado pelo programa OBEDUC/CAPES, cuja finalidade é promover articulações entre as avaliações educacionais e as práticas pedagógicas envolvendo conteúdos de ciências e tecnologias.

Em 2013, o grupo foi composto por seis professores(as) de escolas públicas da Educação Básica, seis estudantes de graduação, três mestrandas e uma doutoranda' ${ }^{1}$. É importante enfatizar que todos os integrantes recebiam bolsas e tinham como compromissos: participar das reuniões semanais do grupo; ler os textos de aprofundamento sobre as bases teórico-metodológicas do projeto mencionadas no item anterior e sobre avaliação; desenvolver propostas colaborativas de intervenção em sala de aula; e trabalhar na perspectiva da reflexão sobre/da ação pedagógica.

Os sujeitos foram identificados por uma denominação alfanumérica, respeitando os compromissos firmados no termo aprovado pelo comitê de ética da Universidade Federal de Santa Catarina, sendo: PE (Professor/a de Escola), EG (Estudante de Graduação) e M (Mestrando/a). Apesar de ser um grupo de formação mista, a maioria era da área de Ciências Biológicas. Um perfil de formação inicial e continuada mais específico dos sujeitos é apresentado no Quadro 1. 
Quadro 1 - Formação inicial e continuada dos integrantes-bolsistas

\begin{tabular}{|c|c|}
\hline Sujeito/ldade & Formação inicial e continuada \\
\hline M1/25 anos & $\begin{array}{l}\text { Graduada em Ciências Biológicas: Bacharelado e } \\
\text { Licenciatura (2012) e Mestranda em ECT. }\end{array}$ \\
\hline M2/32 anos & $\begin{array}{l}\text { Graduada em Ciências Biológicas: Licenciatura (2006). Especialização em } \\
\text { Metodologias de Ensino em Educação Ambiental. Mestranda em ECT. }\end{array}$ \\
\hline M3/não informada & $\begin{array}{l}\text { Graduada em Ciências Biológicas: Bacharelado e Licenciatura (2009). } \\
\text { Especialização em Ciências Biológicas e Educação Ambiental. Mestranda em ECT. }\end{array}$ \\
\hline EG1/26 anos & Graduando em Ciências Biológicas: Licenciatura (Início em 2012). \\
\hline EG2/38 anos & Graduanda em Pedagogia (Início em 2010). \\
\hline $\mathrm{EG} 3 / 24$ anos & Graduando em Ciências Biológicas: Licenciatura (Início em 2007). \\
\hline EG4/23 anos & Graduando em Ciências Biológicas: Licenciatura (Início em 2010). \\
\hline EG5/26 anos & $\begin{array}{l}\text { Graduanda em Ciências Biológicas: Bacharelado } \\
\text { (2007.2) e Licenciatura (Início em 2012.1). }\end{array}$ \\
\hline EG6/28 anos & Graduando em Ciências Biológicas: Bacharelado e Licenciatura (Início em 2010). \\
\hline PE1/32 anos & Graduada em Ciências Biológicas: Bacharelado e Licenciatura (2005). \\
\hline PE2/49 anos & $\begin{array}{l}\text { Graduado em Ciências Biológicas: Bacharelado. } \\
\text { Especialização em Hidroecologia. Mestrado em ECT. }\end{array}$ \\
\hline PE3/46 anos & Graduado em Administração. Graduação em Física: Licenciatura (2009). \\
\hline PE4/50 anos & Graduado em Geografia: Licenciatura (1986). Mestrado em Educação. \\
\hline PE5/não informada & $\begin{array}{l}\text { Graduada em Ciências Biológicas: Bacharelado (1988) e } \\
\text { Licenciatura (1992). Especialização em Hidroecologia. Mestrado } \\
\text { em Engenharia Ambiental. Doutorado em ECT. }\end{array}$ \\
\hline PE6/54 anos & $\begin{array}{l}\text { Graduado em Ciências Biológicas: Bacharelado (1987). } \\
\text { Especialização em Biologia Celular e Molecular (1993). }\end{array}$ \\
\hline
\end{tabular}

Fonte: Elaborado pelas autoras, a partir de dados de um questionário inicial.

Com o grupo acima, desenvolvemos um conjunto de oficinas de leitura com o objetivo de discutir textos que tivessem como referência a tecnologia e suas questões. Esse conjunto de atividades intitulou-se Reflexões sobre a tecnologia em Perspectiva Discursiva em Educação CTS: subsídios para intervenções pedagógicas e análises das questões do Pisa.

As oficinas foram mediadas pela primeira pesquisadora e desenvolvidas em momentos presenciais e não presenciais, totalizando 12 horas de curso: três encontros de duas horas realizados nas salas do Programa de Pós-Graduação em Educação Científica e Tecnológica e seis horas para leitura dos textos e produção de atividades escritas solicitados no percurso. No Quadro 2, apresentamos os textos e os objetivos de cada oficina. 
Quadro 2 - Leituras e atividades das oficinas de leitura

\begin{tabular}{|l|l|l|}
\hline Atividade/Data & Texto & Objetivo(s) \\
\hline $\begin{array}{l}\text { Oficina 01 } \\
-20 / 05 / 2013\end{array}$ & $\begin{array}{l}\text { Sentidos sobre tecnologia em animações } \\
\text { educativas: “De onde vem o papel?” } \\
\text { (GEREMIAS; CASSIANI, 2013). }\end{array}$ & $\begin{array}{l}\text { Investigar os sentidos sobre tecnologia } \\
\text { produzidos no funcionamento da leitura } \\
\text { da animação “De onde vem o papel?". }\end{array}$ \\
\hline $\begin{array}{l}\text { Oficina 02 } \\
-03 / 06 / 2013\end{array}$ & $\begin{array}{l}\text { Introdução à filosofia da } \\
\text { tecnologia (CUPANI, 2011). }\end{array}$ & $\begin{array}{l}\text { Problematizar as diferentes dimensões } \\
\text { da tecnologia, relacionando-as } \\
\text { com as discussões sobre o texto da } \\
\text { análise da animação escolhida. }\end{array}$ \\
\hline $\begin{array}{l}\text { Oficina 03 } \\
-06 / 08 / 2013\end{array}$ & $\begin{array}{l}\text { Introdução escrita por Thomas, } \\
\text { Fressoli e Lalouf (2008) do livro Actos, } \\
\text { actores y artefactos: sociología de la } \\
\text { tecnologia, de Thomas e Buch (2008). }\end{array}$ & $\begin{array}{l}\text { Suscitar reflexões sobre as inter-relações } \\
\text { entre tecnologia e sociedade. }\end{array}$ \\
\hline
\end{tabular}

Fonte: Elaborado pelas autoras.

Os discursos analisados e debatidos neste artigo são referentes ao primeiro dia da oficina, cujo objeto de discussão foi a animação “De onde vem o papel?". Esse material encontra-se disponível no site do Portal do Professor ${ }^{3}$, na área de ensino de Ciências Naturais. Ela integra a coleção “De onde vem?", na qual os temas tratam da origem e dos processos de produção de alguns artefatos construídos pela humanidade, tais como: o plástico, o pão, o avião, o açúcar, o papel, o vidro, a energia elétrica, o fósforo, o livro, a televisão.

Os desenhos dessa série são protagonizados por Kika, uma menina curiosa sobre a origem de objetos, alimentos e fenômenos naturais que fazem parte de seu cotidiano. Em todos os episódios, Kika enfrenta um problema: a falta de tempo ou disposição dos adultos (pais, professores) para responder às suas perguntas. Com o bordão "Ninguém entende as minhas perguntas!", Kika recebe ajuda dos próprios objetos "intrigantes", que ganham vida e solucionam suas dúvidas.

A opção pela animação “De onde vem o papel?" se efetivou após uma leitura preliminar em que vários aspectos foram previamente analisados. Considerávamos que o Sistema Tecnológico (ST) do papel possibilitaria discutir outras questões na formação de professores, tais como: história e tecnologias da escrita e da leitura, relação homem -natureza/tecnologia - sociedade, consumo, desperdício, controvérsias em torno do desaparecimento do papel e substituição dos suportes digitais pelos suportes de escrita e leitura anteriores cuja base é o papel, entre outras.

Uma breve descrição da animação analisada é importante para compreender as leituras produzidas pelos sujeitos da pesquisa. Na tela, vemos diferentes personagens e cenários que ajudam a compor o discurso sobre a 
história do papel e sua produção. Ela se desenvolve, basicamente, em quatro momentos principais: i) $\mathrm{O}$ da sala de aula: em que um aluno joga um avião de papel para Kika contendo um convite para um encontro; ii) O instante que marca o surgimento do papel como narrador da história do papel; iii) A história do papel desde suas origens ao seu processo de produção: na fábrica e na indústria; iv) O retorno de Kika de sua excursão à história da fabricação e origem do papel e a reprodução do que aprendeu aos colegas e à professora.

Figura 1 - Montagem a partir de capturas de tela da animação“De onde vem o papel?"
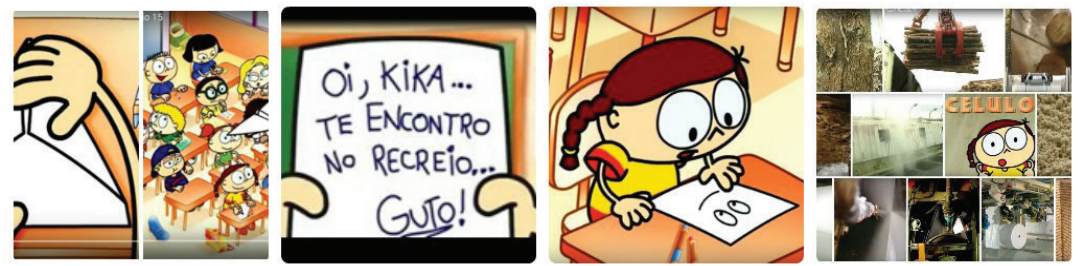

Fonte: Brasil (2001).

Apresentamos, igualmente, uma descrição sintética, elaborada pela primeira autora, do início da narrativa oral e imagética dessa animação, para evidenciar o acontecimento que sinalizou o problema e o tema tecnológico como referente principal:

\footnotetext{
No primeiro momento, vimos uma sala de aula, na qual os alunos estão assistindo às aulas da professora. Uma conta de adição no quadro-negro sugere que a aula é de matemática. No fundo da sala de aula há um menino, sentado na última fila, confeccionando um aviãozinho de papel. Um pouco depois, ele joga o aviãozinho para a menina da frente, a Kika, personagem central da animação. Nele, havia um pequeno texto escrito. Era um convite: - Oi, Kika .... Te encontro na hora do recreio! Guto! Ao ver o avião de papel sobre a carteira de Kika, a professora, em gesto indignado, pergunta: - Kika, de onde vem esse papel? E nesse momento, Kika responde: - Eu é que pergunto, professora: De onde vem o papel?
}

Por meio da descrição acima, buscamos evidenciar que esse é o momento que marca o início da produção do discurso sobre a história do papel que começa a ser narrada à Kika, passando o papel (personificado) a ser o narrador da história.

Participaram da análise da animação referida 12 integrantes bolsistas: M1, M2, M3, PE1, PE2, PE3, PE4, PE5, PE6, EG2, EG3 e EG4. Durante a oficina, 
eles se reuniram em pequenos grupos para debater as questões propostas: Grupo 1: PE1, PE2, PE6 e EG2; Grupo 2: PE3, PE4 e PE5; Grupo 3: PM1, PM2 e PM3; Grupo 4: EG3 e EG4.

Como evidenciamos no quadro geral das oficinas desenvolvidas, a dinâmica de leitura e análise da animação “De onde vem o papel?" se realizou no primeiro momento. Para problematizar alguns aspectos da animação, elaboramos as estratégias de leitura que passamos a descrever.

Primeiramente, passamos a animação sem o som e sem o título. Pedimos que os professores produzissem uma narrativa a partir do encadeamento das imagens. Depois, eles se reuniram nos subgrupos, previamente distribuídos, para debater as seguintes questões:

- Qual é o tema da animação? Que sentidos vocês construíram sobre esse tema a partir da leitura desse vídeo/animação?

No segundo momento, passamos a animação com o som. Os subgrupos voltaram a se reunir e novas questões foram colocadas:

- A narrativa oral corresponde aos sentidos com o que vocês produziram por meio da narrativa visual contada pelo vídeo? Em que correspondeu e em que não correspondeu?

Essa estratégia permitiu entender como as interpretações funcionam quando há texto verbal e quando há somente imagens, ou encadeamentos destas. Somente a discussão no grande grupo foi gravada em áudio e transcrita, posteriormente, pela primeira autora, para ser analisada. É importante lembrar que ao propormos a leitura coletiva dessa animação com os professores, objetivávamos compreender quais sentidos sobre tecnologia poderiam ser produzidos no funcionamento discursivo, ou seja, no momento mesmo em que os sujeitos eram instados a interpretar.

As questões problematizadoras acima descritas e a distribuição em subgrupos durante o processo foram estratégias para mobilizar suas interpretações. Na seção seguinte, discutimos os sentidos sobre tecnologia produzidos pelos sujeitos-leitores durante a passagem da animação sem e com o som.

LEITURAS EM MOVIMENTO: ENTRE O TEXTO IMAGÉTICO E O VERBAL

A análise do material transcrito da primeira oficina, correspondente às questões problematizadoras iniciais, permitiu observar que o primeiro e o terceiro momentos da animação, descritos anteriormente, foram os que mais provocaram discussões e dissensões na leitura realizada pelo grupo. 
Com base na ideia de que os efeitos de leitura da animação são atravessados por outros ditos anteriores e esquecidos (ORLANDI, 2009), em seu funcionamento, os pequenos grupos (1, 2, 3 e 4 ) debateram as questões formuladas e depois socializaram no grande grupo.

O diálogo em torno da animação com o som se concentrou nos deslocamentos dos efeitos de sentido produzidos no momento da leitura imagética. A análise conjunta (com o som) suscitou leituras mais amplas, abrindo espaço para que as críticas ao conteúdo e à forma do material se amplificassem. Nesse processo, o efeito de separação tecnologia - sociedade tornou-se dominante na discussão.

M2 fez um depoimento significativo sobre essa produção de sentidos:

[...] consideramos que as imagens também produzem sentidos [sem som]. Sobre a leitura da animação com o áudio, o discurso oral sedimentou as leituras produzidas sobre a sequência de imagens. Pode-se perceber que $a$ tecnologia parece estar separada nas relações entre o homem e a sociedade, apesar de ela estar presente no contexto social (M2, grifo nosso).

Esse "efeito de separação tecnologia - sociedade" condiz com as discussões realizadas por Thomas (2010) e Benakouche (1999), pois ambos se constituem mutuamente. Na parte grifada, $\mathrm{M} 2$ relaciona esse efeito a uma compreensão instrumental e utilitária do papel.

Entendemos que a percepção de $M 2$ de que as imagens também produzem sentidos já é em si um resultado significativo do trabalho com as interpretações. Contudo, consideramos que o texto verbal estabilizou alguns efeitos de sentido sobre a origem e produção do papel e, ao mesmo tempo, deslocou algumas leituras iniciais.

Ao entendermos que não há neutralidade na linguagem, podemos afirmar que esses efeitos de leitura se manifestam, então, nos dois momentos de formulação: aquela produzida por quem elaborou a animação - antecipando sentidos - e a que se construiu no funcionamento da leitura pelos sujeitos-leitores, em colaboração. Nesses processos de formulação, o leitor se constitui também como autor, na medida em que acrescenta elementos não previstos ou promove uma leitura dos silêncios (ORLANDI, 2007).

Ao analisarmos o funcionamento discursivo, observamos que o grupo, após assistir à animação com o som, retomou os primeiros efeitos de sentido, mas as interpretações individuais e coletivas tornaram-se mais complexas na medida em que novas formulações foram produzidas no diálogo. Vejamos no Quadro 3 os excertos que exemplificam os deslocamentos 
produzidos no processo da leitura sem o som e com o som e, os possíveis temas da animação segundo M1, M2, PE1, PE4, PE5 e EG4.

Quadro 3 - Possíveis temas-referências da animação “De onde vem o papel?". Leituras sem o som e com o som

\begin{tabular}{|c|c|c|}
\hline $\begin{array}{l}\text { Evolução tecnológica do papel/ } \\
\text { produção do papel e formas de } \\
\text { uso e circulação social } \\
\text { 1a leitura (Sem o som) }\end{array}$ & $\begin{array}{l}\text { Origem/história da produção } \\
\text { (relacionada à escrita e à histó- } \\
\text { ria da comunicação) } \\
\text { 2a leitura (Com o som) }\end{array}$ & 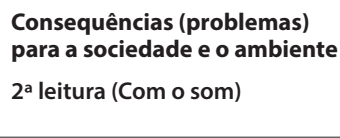 \\
\hline $\begin{array}{l}\text { Acho que o tema da animação } \\
\text { é o papel mesmo, a origem, } \\
\text { a produção mesmo do papel, } \\
\text { como é produzido, a utilização } \\
\text { dele, a origem [...] (M1). } \\
\text { A gente colocou assim: } \\
\text { que o tema seria de onde } \\
\text { vem o papel (PE1). } \\
\text { O nosso tá igualzinho, } \\
\text { papel, origem [...] (PE5). } \\
\text { É lá nos primórdios, né, que } \\
\text { todos escreviam nas pedras, } \\
\text { nas paredes, apareceu o } \\
\text { papiro lá e a coisa da produção } \\
\text { mesmo do papel, como } \\
\text { é produzido [...] (M2). }\end{array}$ & $\begin{array}{l}\text { [...] a impressão que eu tinha } \\
\text { é que ele ia falar da evolução } \\
\text { histórica da comunicação na } \\
\text { espécie humana através do } \\
\text { uso de imagens, símbolos, e } \\
\text { isso não foi explorado (M1). } \\
\text { Foi o caso muito particular } \\
\text { meu. Eu pensei que inicialmente } \\
\text { eles iam falar nas formas de } \\
\text { comunicação, já que houve lá o } \\
\text { aviãozinho que foi uma forma } \\
\text { de comunicar, eu pensei que } \\
\text { ele ia depois dar continuidade } \\
\text { nisso de alguma forma, essa foi } \\
\text { a primeira impressão (PE4). }\end{array}$ & $\begin{array}{l}\text { A gente achava que a professora } \\
\text { falou para não desperdiçar o } \\
\text { papel e na verdade não foi isso, } \\
\text { na verdade ela perguntou de } \\
\text { onde veio [...]. Na verdade, ele } \\
\text { poderia ter falado mais sobre a } \\
\text { reciclagem, desperdício, como } \\
\text { o papel também pode ser feito } \\
\text { através da reciclagem, não só } \\
\text { como uma curiosidade (EG4), } \\
\text { Só como uma alternativa } \\
\text { [reciclagem, desperdício etc.] } \\
\text { e não a questão ambiental } \\
\text { ali, faltou bastante (PE1). } \\
\text { Até a gente já tinha falado, } \\
\text { porque quando apareceu a } \\
\text { imagem das árvores, e depois da } \\
\text { reciclagem, que eles focassem um } \\
\text { pouquinho nisso, né? E não. Foi } \\
\text { muito superficialmente (PE5). }\end{array}$ \\
\hline
\end{tabular}

Fonte: Elaborado pelas autoras.

Os excertos em itálico indicam os deslocamentos produzidos durante o processo da leitura com o som. Ao analisar os efeitos de sentido sobre tecnologia e as questões relativas ao artefato papel, observamos que esta materializou imaginários sobre desperdício e reciclagem desse material, convocando o discurso da Educação Ambiental.

Conforme Karat (2013), questões relativas ao desperdício e à reciclagem são constantemente trabalhadas por professores de Ciências nas escolas, e estão presentes também na mídia e nos discursos políticos (KARAT, 2013; PEREIRA; CASSIANI; LINSINGEN, 2012; COSENZA; MARTINS; LACERDA, 2011). Pereira, Cassiani e Linsingen (2012) escrevem que a Educação Ambiental, comumente desenvolvida nas escolas, tende a ser abordada de modo fragmentado ou isolado do social, do científico e do político. Consideramos que, na análise intersubjetiva da animação, tenhamos problematizado essas relações no desenvolvimento do processo tecnológico de produção e circulação do artefato papel nas aulas. 
Além da materialização do discurso da Educação Ambiental, a ideia de que a narrativa abordaria a história da comunicação e da escrita, na primeira leitura sem o som, apareceu na discussão da animação com o som como algo que seria desenvolvido, mas pouco explorado. Essa interpretação pode ser explicada pela impossibilidade de dissociar a história da tecnologia do papel da história das tecnologias de escrita e, mais amplamente, das tecnologias da comunicação, na qual a escrita se constrói como manifestação de interação humana, de transmissão cultural e da produção de memória.

Se de um lado, a dimensão histórica da tecnologia do papel e da comunicação foi a primeira a se manifestar, de outro, foram produzidos alguns deslocamentos no fio do discurso, no qual se começou a focar nas consequências, nos silêncios em torno dos riscos e problemas e nas possibilidades de solução. Questões sociais, ambientais, políticas, econômicas e científicas relacionadas ao sistema tecnológico desse artefato começaram a ser problematizadas. Esses silêncios sobre o processo tecnológico do papel foram interpretados, pelo grupo, como efeitos de uma perspectiva neutral e instrumentalista de tecnologia bastante arraigada na sociedade, inclusive nas comunidades acadêmicas. Eles se materializaram em vários momentos do diálogo. Exemplificamos com os excertos transcritos e sistematizados no Quadro 4.

Quadro 4 - Exemplos do processo de construção de novas leituras sobre a animação "De onde vem o papel?"

\begin{tabular}{|c|c|c|}
\hline $\begin{array}{l}\text { Separação entre huma- } \\
\text { nos e máquinas/tecnolo- } \\
\text { gia e sociedade }\end{array}$ & Silêncio sobre as questões socioambientais & $\begin{array}{l}\text { Silêncio sobre as ques- } \\
\text { tões científicas }\end{array}$ \\
\hline $\begin{array}{l}\text { A gente concordou aqui } \\
\text { que toda a animação } \\
\text { mostra muito mais as } \\
\text { máquinas e tu não vê } \\
\text { nenhum homem lidando } \\
\text { ali com as máquinas. } \\
\text { Aparece só o homem no } \\
\text { início, ali desenhando nas } \\
\text { cavernas e depois tu não } \\
\text { vês homem nenhum, só } \\
\text { máquina. Então, a gente } \\
\text { achou um ponto de vista } \\
\text { essencialmente tecnológico } \\
\text { e pouco social (PE1). }\end{array}$ & $\begin{array}{l}\text { Correspondeu essa questão do } \\
\text { silenciamento das questões sociais (PE2). } \\
\text { A gente também achou no início que ela ia falar } \\
\text { do desperdício, mas não foi disso, e ali também } \\
\text { com relação ao que ela falou, aparece ali } \\
\text { bastante as imagens das árvores e eu achei que } \\
\text { falaria bastante dos recursos naturais, e uma } \\
\text { coisa que eu percebi é que, poxa, você só usa } \\
\text { a madeira para fazer papel? Ea quantidade de } \\
\text { água que você usa para fazer papel? Não se vê } \\
\text { em nenhum momento, falou pouco disso, dos } \\
\text { recursos naturais usados na fabricação (PE1). }\end{array}$ & $\begin{array}{l}\text { E a sugestão da produção } \\
\text { da celulose também, que } \\
\text { não é um conhecimento } \\
\text { de todos, é mais químico } \\
\text { também (PE6). }\end{array}$ \\
\hline
\end{tabular}

Fonte: Elaborado pelas autoras.

Consideramos que as leituras anteriores, as experiências profissionais e as discussões teóricas ligadas às áreas de ensino dos sujeitos que participaram da análise da animação, ao serem integradas ao diálogo, contribuíram 
com interpretações de caráter mais crítico, produzindo deslocamentos nas leituras iniciais. Citamos como exemplo a concentração no debate, conforme discursos grifados acima, em torno da separação tecnologia - sociedade e dos silêncios sobre questões ambientais, científicas e sociais percebidos durante a análise conjunta da animação em sua totalidade.

\section{CONSIDERAÇÕES: SOBRE PROBLEMATIZAR E DESLOCAR IDEIAS PRONTAS}

Os exemplos de excertos de análise da animação "De onde vem o papel?", produzidos pelos integrantes do grupo OBEDUFSC - Ciências, são demonstrativos do processo de produção de sentidos e do funcionamento da leitura da animação cujo referente principal é o artefato tecnológico papel. Consideramos que as leituras realizadas nesse processo de interpretação coletiva contribuíram para problematizar questões sobre tecnologia pertencentes às discussões que temos realizado no âmbito da Perspectiva Discursiva em Educação CTS.

Percebemos que as leituras produzidas a partir das imagens se desestabilizaram com a apresentação do texto verbal. Consideramos que as questões colocadas pela primeira autora/mediadora no processo foram fundamentais para a produção de um discurso mais polêmico e, desse modo, para a negociação e produção de novas leituras.

Ao procurarmos estabelecer uma relação entre o que vem sendo debatido sobre tecnologia nos textos teóricos e os discursos formulados pelos sujeitos da pesquisa, percebemos a teia de relações políticas, econômicas e sociais que se materializam nas tecnologias e vice-versa, corroborando a noção de sociotécnica defendida nos ESCT.

A partir da análise das interpretações dos sujeitos da pesquisa, na qual o texto verbal e imagético são confrontados e problematizados, pudemos perceber o modo como outros discursos, provindos de outros lugares e campos de conhecimento, sobre a produção tecnológica, se materializaram no discurso dos professores, atualizando questões como: i) efeitos, problemas e riscos tecnológicos $x$ possibilidades de redução destes (solução); ii) compreensão da tecnologia ora como solução para todos os problemas que a sociedade enfrenta (leitura salvacionista), ora como responsável direta pelos problemas sociais e ambientais (leitura destrutiva); iii) silenciamentos das relações entre ciência, tecnologia e sociedade nos materiais educativos desenvolvidos para a área de Ensino de Ciências. 
Em síntese, a análise coletiva da animação educativa"De onde vem o papel?" proporcionou elementos para problematizar e compreender o que é dito - seus equívocos e seus descolamentos -, mas, também, os silêncios sobre tecnologia e suas questões, contribuindo para pensar o desenvolvimento de temas sociotécnicos na formação de professores.

\section{TECHNOLOGY AS A PROBLEM IN SCIENCE, TECHNOLOGY, AND SOCIETY EDUCATION: ANALYSES OF A READING WORKSHOP IN SCIENCE TEACHER EDUCATION}

AвSTRACT: On the basis of a Discursive Perspective in Science, Technology, and Society (STS) Education, we investigated the meanings about technology which were produced during the analysis of an educational animation on the origin and the production of the artefact paper, that was carried out with members of the group Observatório da Educação (Education Observatory) of the Universidade Federal de Santa Catarina (Federal University of Santa Catarina) (OBEDUFSC - Ciências). In the analysis of the process, we noticed the materialisation, in the research participants' discourse, of questions that were debated during the STS studies, such as: i) problem $x$ technological solution; ii) salvationist $x$ destructive reading of technology; iii) silencing of the STS relations. In short, the research provided elements to problematize and to understand what is being said, but also the silences about technology and its questions. Lastly, it also contributed to think about the development of technological themes in the science teacher education.

KEYwords: STS Education. Science teacher education. Technology. Paper.

\section{LA TECNOLOGÍA COMO PROBLEMA EN LA EDUCACIÓN EN CIENCIA, TECNOLOGÍA Y SOCIEDAD: ANÁLISIS DE UN TALLER DE LECTURA EN LA FORMACIÓN DE PROFESORES DE CIENCIAS}

Resumen: A partir de una Perspectiva Discursiva en Educación en Ciencia, Tecnología y Sociedad (CTS), investigamos los sentidos sobre tecnología producidos durante el análisis conjunto de una animación educativa sobre el origen y la producción del artefacto papel, realizada con integrantes del grupo Observatório da Educação, da Universidade Federal de Santa Catarina - Ciências (OBEDUFSC - Ciências). En el análisis de ese proceso, percibimos, en el discurso de los sujetos de la investigación, 
la materialización de cuestiones debatidas en los estudios CTS, tales como: i) problema $x$ solución tecnológica; ii) lectura salvacionista $x$ destructiva de la tecnología; iii) silenciamientos de las relaciones CTS. En síntesis, la pesquisa proporcionó elementos para problematizar y comprender lo que es dicho, pero, también los silencios sobre la tecnología y sus cuestiones, contribuyendo a pensar el desarrollo de temas tecnológicos en la formación de profesores de ciencias.

Palabras-clave: Educación CTS. Formación de profesores de Ciencias. Tecnología. Papel.

\section{NOTAS}

1) Primeira pesquisadora.

2) Primeira análise realizada pelas pesquisadoras e apresentada no IX Encontro Nacional de Pesquisa em Educação em Ciências.

3) Portal criado em 2008, em parceria com o Ministério da Ciência e Tecnologia, com o objetivo de apoiar os processos de formação dos professores e as práticas pedagógicas em sala de aula.

\section{REFERÊNCIAS}

ABREU, T. B. de; FERNANDES, J. P.; MARTINS, I. Levantamento sobre a produção CTS no Brasil no período de 1980-2008 no campo de ensino de ciências. Alexandria: Revista de Educação em Ciência e Tecnologia, v. 6, n. 2, p. 3-32, 2013. Disponível em: <https://periodicos.ufsc.br/index.php/alexandria/article/viewFile/37953/28981>. Acesso em: 15 jun. 2016.

ACEVEDO-DÍAZ, J. A et al. Creencias sobre la tecnología y sus relaciones con la ciencia. Revista Electrónica de Enseñanza de las Ciencias, v. 2, n. 3, 2003. Disponível em: <http:// reec.uvigo.es/volumenes/volumen2/REEC_2_3_9.pdf>. Acesso em: 16 jun. 2016.

AULER, D.; DELIZOICOV, D. Educação CTS: articulação entre pressupostos do educador Paulo Freire e referenciais ligados ao movimento CTS. In: Seminário Ibérico CTS no ensino das ciencias: Las Relaciones CTS en la Educación Científica, 2006, Málaga. Anais... Málaga: Universidade de Málaga, 2006. v. 4, p. 1-7. Disponível em: <http:// www.educadores.diaadia.pr.gov.br/arquivos/File/2010/artigos_teses/fisica/educ_ cts_delizoicov_auler.pdf $>$. Acesso em: 20 mar. 2015.

BENAKOUCHE, T. Tecnologia é sociedade: contra a noção de impacto tecnológico. Cadernos de Pesquisa, [s.I.], n. 17, set. 1999.

BRASIL. Ministério da Educação. TV Escola. De onde vem o papel? (Coleção De onde vem?). Brasília: MEC/TV Escola, 2001. Disponível em: <http://tvescola.mec.gov.br/ tve/video/de-onde-vem-de-onde-vem-o-papel>. Acesso em: 15 fev. 2016. 
CASSIANI, S. et al. O grupo dicite - discursos da ciência e da tecnologia na educação. Ciência e Ensino, v. 3, n. 1, p. 1-19, 2014. Disponível em: <http://prc.ifsp.edu.br/ojs/ index.php/cienciaeensino/article/view/898/361>. Acesso em: 15 jun. 2016.

COSENZA, A.; MARTINS, I.; LACERDA, V. S. Imagens, textos e (em) discursos: representações de efeitos socioambientais da exploração de petróleo em Macaé, RJ. In: Encontro Nacional de Pesquisa em Educação em Ciências, 7, 2011, Campinas, Anais... Campinas: Associação Brasileira de Pesquisa em Educação em Ciências, 2011. Disponível em: <http://www.nutes.ufrj.br/abrapec/viiienpec/resumos/R1227-1.pdf>. Acesso em: 15 jun. 2016.

CUPANI, A. Filosofia da tecnologia: um convite. Florianópolis: Ed. UFSC, 2011.

FENSHAM, P. J. Approaches to the teaching of STS in science education. International Journal of Science Education, v. 10, n. 4, p. 346-356, 1988. Disponível em: <http:// dx.doi.org/10.1080/0950069880100402>. Acesso em: 20 mar. 2015.

FERNÁNDEZ, I et al. El olvido de la tecnología como refuerzo de las visiones deformadas de la ciencia. Revista Electrónica de Enseñanza de las Ciencias, v. 2, n. 3, p. 331352, 2003. Disponível em: <http://reec.uvigo.es/volumenes/volumen2/REEC_2_3_8. pdf $>$. Acesso em: 15 jun. 2016.

FISCHER, R. M. B. Mídia, máquinas de imagens e práticas pedagógicas. Revista Brasileira de Educação, Rio de Janeiro, v. 12, n. 35, p. 290-299, maio/ago. 2007. Disponível em: <http://www.scielo.br/pdf/rbedu/v12n35/a09v1235.pdf>. Acesso em: 15 jun. 2016.

GEREMIAS, B. M.; CASSIANI, S. Sentidos de tecnologia em animações educativas: De onde vem o papel? In: Encontro Nacional de Pesquisa em Educação em Ciências, 9, 2013, Águas de Lindóia, SP. Anais... Águas de Lindoia, SP: Associação Brasileira de Pesquisa em Educação em Ciências, 2013. Disponível em: <http://www.nutes.ufrj. br/abrapec/ixenpec/atas/resumos/R0712-4.pdf>. Acesso em: 15 jun. 2016.

KARAT, M. T. Contribuições da epistemologia e da análise de discurso para o ensino dos resíduos sólidos. In: Encontro Regional Sul de Ensino de Biologia (EREBIO-SUL), 6, 2013, Santo Angelo. Anais... Santo Ângelo: Furi, 2013. Disponível em: <http:// santoangelo.uri.br/erebiosul2013/anais/wp-content/uploads/2013/07/comunicacao/13632_300_Marinilde_Tadeu_Karat.pdf>. Acesso em: 15 jun. 2016.

LAYTON, D. Revaluing the T in STS. International Journal of Science Education, v. 10, n. 4, p. 367-378, 1988. Disponível em:<http://dx.doi.org/10.1080/0950069880100404>. Acesso em: 31 jan. 2016.

LINSINGEN, I. von (Coord.). Reflexões e práticas pedagógicas nas ciências naturais: leituras das avaliações nacionais como subsídios da educação. Florianópolis: Capes, Observatório da Educação, 2013. Disponível em <http://dicite.paginas.ufsc.br/nossos-projetos/obeduc2013-2016/>. Acesso em: 20 maio 2014. 
; CASSIANI, S. Educação CTS em perspectiva discursiva: contribuições dos estudos sociais da ciência e da tecnologia. Redes, v. 16, n. 31, p. 163-182, 2010. Disponível em: <http://www.redalyc.org/articulo.oa?id=90721346008>. Acesso em: 20 maio 2014. NASCIMENTO, T. G.; LINSINGEN, I. von. Articulações entre o enfoque CTS e a pedagogia de Paulo Freire como base para o ensino de ciências. Convergencia, Revista de Ciencias Sociales, v. 13, n. 42, p. 95-116, sep./dic. 2006. Disponível em: <http://www. educadores.diaadia.pr.gov.br/arquivos/File/2010/artigos_teses/quimica/aticulacoes_enfoq_cts.pdf>. Acesso em: 15 jun. 2016.

NEDER, R. T. Tecnologia sob os direitos humanos de quinta geração? (A democratização da gestão tecnológica). In: CTS: ciência-tecnologia-sociedade e a produção de conhecimento na universidade. Brasília: Observatório do Movimento pela Tecnologia Social na América Latina, 2013. p. 141-166. Disponível em: <http:// banqueteio.net/eudora/LivroVermelhoCicloll.pdf>. Acesso em: 8 dez. 2015.

NIEZWIDA, N. R. A. Educação tecnológica com perspectiva transformadora: a formação docente na constituição de estilos de pensamento. 2012. 407 f. Tese (Doutorado em Educação Científica e Tecnológica). Programa de Pós-Graduação em Educação Científica e Tecnológica, Universidade Federal de Santa Catarina, 2012.

ORLANDI, E. P. Análise de discurso: conversa com Eni Orlandi. In: BARRETO, R. G. Entrevista. Teias, Rio de Janeiro, ano 7, n. 13-14, jan./dez. 2006. Disponível em: <http://periodicos. proped.pro.br/index.php/revistateias/article/viewFile/210/209>. Acesso em: 9 jul. 2014.

. As formas do silêncio no movimento dos sentidos. 6. ed. Campinas: Editora da Unicamp, 2007.

. Discurso e texto: formulação e circulação de sentidos. 3. ed. Campinas: Pontes Editores, 2008.

Análise de discurso: princípios e procedimentos. 8. ed. Campinas: Editora Pontes, 2009.

. Discurso em análise: sujeito, sentido, ideologia. Campinas: Pontes Editores, 2012. PEREIRA, P. B. P.; CASSIANI, S.; LINSINGEN, I. von. O meio ambiente e a construção de sentidos no ensino fundamental. Amazônia, v. 9, n. 17, p. 76-88, jul./dez. 2012. Disponível em: <http://www.ppgecm.ufpa.br/revistaamazonia/wp-content/uploads/2013/04/vol9n17_art05.pdf>. Acesso em: 15 jun. 2016.

PREMEBIDA, A.; NEVES, F. M.; ALMEIDA, J. Estudos sociais em ciência e tecnologia e suas distintas abordagens. Sociologias, Porto Alegre, ano 13, n. 26, p 22-42, jan./ abr. 2011. Disponível em: <http://www.ufrgs.br/temas/artigos/2011_estudos_sociais_em_ciencia_e_tecnologia.pdf>. Acesso em: 30 jan. 2016.

RAMOS, M. B. Discursos sobre ciência e tecnologia no Jornal Nacional. 2006. 137 f. Dissertação (Mestrado em Educação Científica e Tecnológica) - Programa de Pós-Graduação em Educação Científica e Tecnológica, Universidade Federal de Santa Catarina, Florianópolis, 2006. 
STRIEDER, R. B. Abordagens CTS na educação científica no Brasil: sentidos e perspectivas. 2012. 283 f. Tese (Doutorado em Ensino de Ciências) - Instituto de Física e Química, Universidade de São Paulo, 2012. Disponível em: <http://www.teses.usp.br/ teses/disponiveis/81/81131/tde-13062012-112417/pt-br.php>. Acesso em: 20 maio 2014.

THOMAS, H. Les estudios sociales de la tecnología en la América Latina. Íconos, n. 37, p. 35-53, maio 2010. Disponível em: <http://www.flacso.org.ec/docs/i37thomas. pdf $>$. Acesso em: 15 jun. 2016.

; FRESSOLI, M.; LALOUF, A. Introducción. In: THOMAS, H.; BUCH, A. (Comp.). Actos, actores y artefatos: sociología de la tecnología. 1. ed. Bernal: Universidad Nacional de Quilmes, 2008.

VELHO, L.; VELHO, P. A controvérsia sobre o uso de alimentação alternativa no combate à subnutrição no Brasil. História, Ciências, Saúde, Manguinhos, Rio de Janeiro, v. 9, n. 1, p. 125-157, jan./abr. 2002. Disponível em: <http://www.scielo.br/pdf/hcsm/ v9n1/a07v9n1.pdf>. Acesso em: 25 jan. 2016.

Bethania Medeiros Geremias: Professora Adjunta do Departamento de Educação da Universidade Federal de Viçosa (UFV). Doutora e mestre em Educação Científica e Tecnológica pelo Programa de Pós- Graduação em Educação Científica e Tecnológica (PPGECT-UFSC). Doutorado Sanduíche na Université de Dijon e mestrado em Ciências da Educação pela Université de Nantes. Pedagoga: Orientação Educacional e Magistério das Séries Iniciais, pela Universidade do Estado de Santa Catarina (UDESC).

E-mail:bmgeremias@ufv.br

SuZANi Cassiani: Professora associada no Departamento de Metodologia de Ensino da Universidade Federal de Santa Catarina. Bolsista produtividade $P Q$ do $C N P q$ - 1D. Líder do Grupo de Pesquisa Discursos da Ciência e da Tecnologia na Educação (DICITE) do Programa de Pós-Graduação em Educação Científica e Tecnológica. Coordenadora do Programa de Qualificação de Docentes e Ensino de Língua Portuguesa da CAPES, em Timor-Leste. Membro da Diretoria da Associação Brasileira de Pesquisa em Educação em Ciências. Realizou pós-doutoramento (estágio sênior) financiado pela CAPES, no Centro de Estudos Sociais da Universidade de Coimbra.

E-mail: suzanicassiani@gmail.com 
